\title{
- Electrical properties of Co-Zn ferrite Doped with Silicon \\ IJCRR
}

Section: General

Science

Sci. Journal

Impact Factor

4.016

ICV: 71.54

\author{
S. S. Shinde
}

Department of Physics, A.S.C. College, Naldurg -413602. Tq. Tuljapur, Dsit. Osmanabad. (M.S.) India.

\section{ABSTRACT}

Ferrites of the composition Co0.7+x Zn0.3 Six Fe2-2x O4 ( $x=0.0,0.1,0.15,0.2,0.25,3,4)$ are prepared by double sintering ceramic method. X-ray diffraction patterns of all the samples show cubic spinal phase. By comparing the calculated and observed X-ray intensity ratios $1220 / 1400$ and 1400/ 1422 and using site preference of various ions, the cation distribution of the present system is determined. At lower concentration of Si up to $x=0.15$, the dc resistively ( $\rho d c)$ increases and for $x>0.15$, $\rho d c$ is found to decrease. With increase in temperature, dc resistively decreases except for higher concentration of $\mathrm{Si}(\mathrm{x}=0.3$ and 0.4$)$ which show increase in resistivity at lower temperature. Activation energy values show one to one correspondence with resistivity values. Curie temperature is found to decrease with increase in Si concentration.

Key Words: Lattice Parameter, D.C. Resistivity, Activation Energy

\section{INTRODUCTION}

Studies of spinel ferrites are highly relevant to modern technologies. So that the synthesis of ferrites have become an important part of modern ceramic research. Cobalt-Zinc ferrite is one of the soft ferrites used in electronic devices such as transformer core, electric motors and generators. It is observed that incorporation of diamagnetic, tetravalent and pentavalent ions in the ferrites sufficiently improves their electrical properties. To increase the resistivity and develop the desired microstructure, tetravalent ions like Ti, Sn and $\mathrm{Si}$ are substituted in mixed ferrites. It is observed that the resistivity increases with increase in $\mathrm{Si}^{4+}$ content in $\mathrm{Ni}-\mathrm{Cd}$ ferrite [1]. The addition of tetravalent ions like Ti and $\mathrm{Si}$ in Co-Cd mixed ferrite have been studied to understand the role of these ions on the physical properties of ferrites [2]. In our previous study we have reported electrical and dielectric properties of Si substituted Co ferrite [3]. As an extension of this work, present paper reports the effect of $\mathrm{Si}^{4+}$ substitution on electrical properties of $\mathrm{Co}-\mathrm{Zn}$ mixed ferrite.

\section{MATERIAL AND METHODS}

The ferrites with chemical formula $\mathrm{Co}_{0.7+\mathrm{x}} \mathrm{Zn}_{0.3} \mathrm{Si}_{\mathrm{x}} \mathrm{Fe}_{2-2 \mathrm{x}} \mathrm{O}_{4}$ (Where $x=0.0,0.1,0.15,0.2,0.25,0.3,0.4$ ) were prepared by standard double sintering ceramic technique. AR grade oxides $\mathrm{Fe}_{2} \mathrm{O}_{3}, \mathrm{CoO}, \mathrm{ZnO}$ and $\mathrm{SiO}_{2}$ were thoroughly mixed in required proportions. The samples were then presintered at $700^{\circ} \mathrm{c}$ for $12 \mathrm{hr}$ in air medium and slowly cooled to room temperature. The presintered powder was milled and sieved to a fine powder. Pellets were prepared by subjecting a small quantity of powder to a pressure of about $12 \times 10^{6} \mathrm{~kg} / \mathrm{m}^{2}$ by keeping it in a die of diameter $1 \mathrm{~cm}$ and these pellets were finally sintered at $1050^{\circ} \mathrm{C}$ for about $24 \mathrm{hr}$ in air medium. Cooling to room temperature was carried out at the rate of $80^{\circ} \mathrm{c}$ per hr.

The structural and physical properties of the prepared samples were determined by X-ray powder diffractometry technique. The X-ray diffraction patterns were recorded on a diffractometer PW710 using $\mathrm{Cu}-\mathrm{K}$ radiation of wavelength $1.54060 \mathrm{~A}^{0}$ in the range of $2 \theta=10^{\circ}$ to $90^{\circ}$ and scanning rate of $1^{0}$ per minute.

The temperature and composition dependence of dc resistively $\left(\rho_{\mathrm{dc}}\right)$ of all samples was studied by two probe method. For good electrical ohmic contact the pellets were polished and silver pasted on both the surfaces.

\section{RESULTS}

The room temperature X-ray diffraction patterns of all the samples of the present series confirm the single phase formation of spinel. Typical X-ray diffraction patterns of the samples with Si concentration $x=0.2$ and $x=0.4$ are shown

\section{Corresponding Author:}

S.S. Shinde, Department of Physics, A.S.C. College, Naldurg -413602. Tq. Tuljapur, Dsit. Osmanabad. (M.S.) India. Mobile: 7719028059,9423354546; E-mail: sureshshinde186@gmail.com

ISSN: 2231-2196 (Print)

Received: 04.04 .2017
ISSN: 0975-5241 (Online)

Revised: 19.04.2017
DOI: http://dx.doi.org/10.7324/IJCRR.2017.9968

Accepted: 30.04 .2017 
in Figure.1. The values of lattice constant ' $a$ ' listed in Table 1 show slow decrease with increasing Si content from $x=$ 0.1 to 0.4 .

According to site preference clergies given by Miller [5], $\mathrm{Fe}^{3+}$ ions get statistically distributed over B-site and A-site, $\mathrm{Co}^{2+}$ has a strong preference on $\mathrm{B}$-site and $\mathrm{Zn}^{2+}$ has strong preference for A-site. Also it is reported that $\mathrm{Si}^{4+}$ ions have strong preference to A-site [6]. X-ray intensities were calculated using the formula suggested by Buerger [7].

$$
\mathrm{I}_{\mathrm{hkl}}=\left|\mathrm{F}_{\mathrm{hkl}}\right|^{2} \mathrm{PL}_{\mathrm{p}}
$$

where notations have their usual meanings. By comparing the calculated and observed X-ray intensity ratios $\mathrm{I}_{220} / \mathrm{I}_{400}$ and $\mathrm{I}_{400} / \mathrm{I}_{422}$ and using the above stated site preference of various ions, the cation distribution of the present system can be written as

For $x=0.0\left(\mathrm{Zn}_{0.3} \mathrm{Fe}_{0.7}\right)\left[\mathrm{Co}_{0.7} \mathrm{Fe}_{1.2}\right]$

For $x=0.1$ to 0.4 (Co0.05 Zn0.3 Si0.05+y Fe0.6-y)

[Co0.75+y Si0.05Fe1.2-y]

Where $x=0.1+\mathrm{y}, \mathrm{y}=0.0,0.05,0.1,0.15,0.2,0.3$

The values of dc resistivity $\rho_{\mathrm{dc}}$ obtained at $400 \mathrm{~K}$ are listed in Table 1. It is evident that dc resistively increases with increase in Si concentration up to $x=0.15$ and then decreases with increase in $x$.

The activation energies (Eg) in ferrimagnetic and paramagnetic regions obtained from the plots of $\log \rho_{\mathrm{dc}}$ and temperature are listed in Table1. The activation energy values in the paramagnetic regions are higher than that in ferrimagnetic region. This is in agreement with the theory developed by Irkhin and Turvo [12].

The values of Curie temperature ( $\mathrm{Tc}$ ) determined from the resistivity plots are listed in Table 1 . It is evident that the $\mathrm{Cu}-$ rie temperature decreases with increasing Si concentration

\section{DISCUSSION}

Decrease in lattice constant ' $a$ ' with increasing Si content from $x=0.1$ to 0.4 show that present samples obey Vegard's law [4]. Usually in a solid solution of spinels within the miscibility range, a linear change in the lattice constants in observed [4]. The linear slow decrease in lattice constant in the present system can be explained on the basis of following facts.

(i) The larger $\mathrm{Fe}^{3+}$ ions $\left(0.64 \mathrm{~A}^{0}\right)$ are replaced by smaller $\mathrm{Si}^{4+}$ ions $\left(0.42 \mathrm{~A}^{0}\right)$ on $\mathrm{A}$ site so that ionic radius at $\mathrm{A}$ site decreases.

(ii) The smaller $\mathrm{Fe}^{3+}$ ions $\left(0.64 \mathrm{~A}^{0}\right)$ are replaced by larger $\mathrm{Co}^{2+}\left(0.72 \mathrm{~A}^{0}\right)$ on $\mathrm{B}$ site so that ionic radius of $\mathrm{B}$ site increases.

(iii) The difference in ionic radii of $\mathrm{Fe}^{3+}$ and $\mathrm{Si}^{4+}\left(0.22 \mathrm{~A}^{0}\right)$ on A Site is more than the difference in the ionic radii of $\mathrm{Fe}^{3+}$ and $\mathrm{Co}^{2+}\left(0.12 \mathrm{~A}^{0}\right)$ on $\mathrm{B}$ site. Thus decrease in ionic radius of $\mathrm{A}$ site is greater than the increase in ionic radius of $\mathrm{B}$ site.

Due to complex structural composition of these ferrites, the conduction mechanism can be attributed to a combination of several processes. $\mathrm{Fe}^{2+}$ ions are formed due to partial reduction of small fraction of $\mathrm{Fe}^{3+}$ to $\mathrm{Fe}^{2+}$ ions due to volatilization of $\mathrm{Zn}$ at elevated firing temperature during sintering process [9]. In the present system, $2 \mathrm{Fe}^{3+}$ ions are replaced by $\mathrm{Si}^{4+}$ ions and $\mathrm{Co}^{2+}$ ions. Also $\mathrm{CoO}$ has an affinity for oxidation resulting in the formation of $\mathrm{Co}^{3+}$ ions. So increasing resistivity of the system with increase of Si content up $x=0.15$ may be due to electron - hole compensation.

The decrease in $\rho_{\mathrm{dc}}$ with increase of Si content from $x=0.2$ to 0.4 may be attributed to the presence of larger number of cobalt ions on B-site, which favor the hoping mechanism between $\mathrm{Co}^{2+}$ and $\mathrm{Co}^{3+}$ ions. Thus P-type, i.e. hole hoping between $\mathrm{Co}^{2+}$ and $\mathrm{Co}^{3+}$ in predominant conduction mechanism in the ferrites containing higher concentration of cobalt. These observations are consistent with the earlier reported results [10].

Variation of $\log \rho_{\mathrm{dc}}$ with temperature (Fig.2) show decrease in resistivity with increasing temperature. This indicates semiconductor behavior having negative temperature coefficient of resistance. For higher concentrations of Si with $x$ $=0.3$ and $0.4, \log \rho_{\mathrm{dc}}$ is found to increase with temperature up to about $250 \mathrm{~K}$. (Figure 2.) This anomalous variation of resistively at lower temperature for $\mathrm{Si}$ concentration $x=0.3$ and 0.4 may be due to ionic drift current. The variation of $\rho_{\mathrm{dc}}$ with temperature can be attributed to current due to electrons in conduction band, current due to electro hoping and ionic drift current [11]. The present results indicate that contribution from ionic drift current is more predominant in the anomalous region of $\rho_{\mathrm{dc}}$ for samples with Si concentration $x$ $=0.3$ and 0.4 . The ionic contribution becomes negligible at higher temperatures and $\rho_{\mathrm{dc}}$ becomes entirely electronic.

The activation energy $(\mathrm{Eg})$ values are found to correspond to the dc resistivity values of the samples. The plots of $\log \rho_{\mathrm{dc}}$ against reciprocal of temperature show abrupt change in the slope at the transition temperature. The change in the slope of the curves may be due to change in conduction mechanism [13] or it may be due to phase transition..

The decrease in Curie temperature $\mathrm{Tc}$ is because of net reduction of $\mathrm{Fe}^{3+}$ ions which reduces the number of active magnetic linkages

\section{CONCLUSION}

Decrease in Lattice constant is due to replacement of larger ions by smaller ions. Decrease in X-ray density shows that decrease in mass overtakes decrease in volume of unit cell. Particle size is found to be consistent with the ceramically 
prepared ferrites. Increase in dc resistivity for lower concentration of $\mathrm{Si}$ is due to electron hole compensation while decrease in $\rho_{\mathrm{dc}}$ at higher concentration of $\mathrm{Si}$ is due hole hoping between $\mathrm{Co}^{2+}$ and $\mathrm{Co}^{3+}$ ions. The anomalous variation of resistivity for higher concentration of $\mathrm{Si}$ is due to ionic drift current.

\section{ACKNOWLEDGEMENT}

Author acknowledges the immense help received from the scholars whose articles are cited and included in references of this manuscript. The author is also grateful to authors/editors/publishers of all those articles, journals and books from where the literature for this article has been reviewed and discussed.

Conflict of Interest: Author declare no conflict of interest.

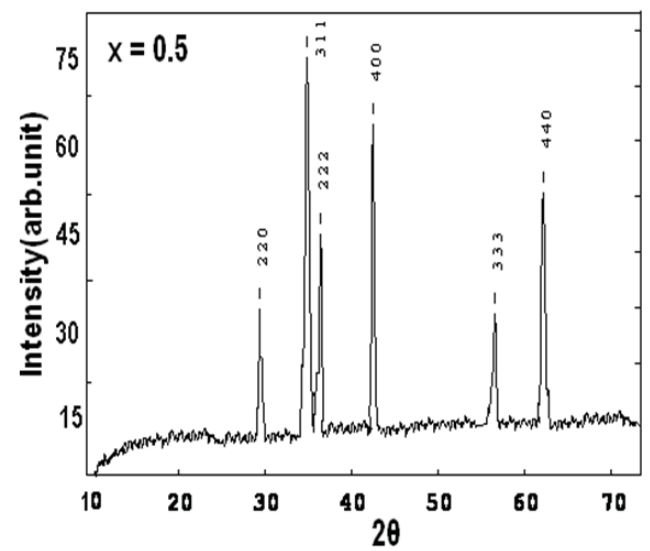

Figure 1: Typical X-ray diffractograms of the $\mathrm{Co}_{0.7+x} \mathrm{Zn}_{0.3} \mathrm{Si}_{\mathrm{x}} \mathrm{Fe}_{2-}$ ${ }_{2 \mathrm{x}} \mathrm{O}_{4}$ for $\mathrm{x}=0.1$.

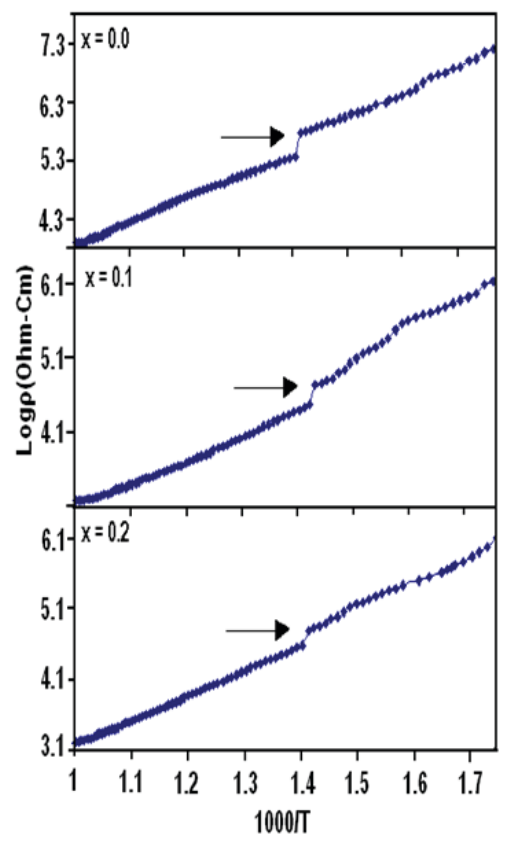

Figure 2: Plots of $\log \rho_{d c}$ vs $10^{4} / \mathrm{T}$ for $\mathrm{Si}$ concentration in $\mathrm{Co}_{0.7+x} \mathrm{Zn}_{0.3} \mathrm{Si}_{x} \mathrm{Fe}_{2-2 x} \mathrm{O}_{4}$.
Table 1: D.C. resistivity, activation energy and Curie temperature.

\begin{tabular}{ccccc}
$\begin{array}{c}\text { Composition. } \\
\mathbf{x}\end{array}$ & $\begin{array}{c}\text { DC resis- } \\
\text { tivity } \\
\text { at } 400 \mathrm{~K} \\
\rho_{\mathrm{dc}}(\Omega-\mathrm{cm})\end{array}$ & $\begin{array}{c}\text { Activation } \\
\text { energy } \Delta \mathrm{E} \\
(\mathrm{ev})\end{array}$ & $\begin{array}{c}\text { Curie } \\
\text { Para }\end{array}$ & $\begin{array}{c}\text { Ferri } \\
\text { temperature }\end{array}$ \\
$\begin{array}{cccc}\text { Tc }(\mathrm{K}) \\
0.0\end{array}$ & $1.31 \times 10^{6}$ & 0.59 & 0.50 & 630 \\
0.10 & $3.53 \times 10^{6}$ & 0.63 & 0.63 & 580 \\
0.15 & $3.92 \times 10^{6}$ & 0.79 & 0.79 & 576 \\
0.20 & $2.84 \times 10^{6}$ & 0.71 & 0.71 & 570 \\
0.25 & $1.61 \times 10^{6}$ & 0.65 & 0.65 & 563 \\
0.30 & $0.34 \times 10^{6}$ & 0.55 & 0.55 & 550 \\
0.40 & $0.07 \times 10^{6}$ & 0.54 & 0.54 & 525 \\
\hline
\end{tabular}

\section{REFERENCES}

1. M.G. Patil, V.C. Mahajan, A. K. Ghatege and S. A. Patil Indian J. of Pure and applied Phy,,34:166:1996

2. V. C. Mahajan, Ph.D. Thesis, Shivaji University, Kolhapur (1995).

3. S. S. Shinde, K. M. Jadhav, Mater Lett.,37: 63: 1998.

4. C. G. Whinfrey, D. W. Eckart, A. Taubar, J.Am. Chem. Soc., 82:2695:1960

5. A. J. Miller, Appl. Phys., 30:248:1959.

6. S.S. Shinde, K.M. Jadhav, G. K. Bichile, B. S. Trivedi and R. G. Kulkarni, Bull. Mat. Sci. 21:409:1998.

7. M. J. Burger J. Crystal Structure Analysis, John Wiley, New York (1960).

8. B. D. Cullity, Elements of X-ray diffraction, Addision Wesely, Reading, Mass, 1959.

9. L. G. Van Uitert, Proc. IRE (USA), 1294 (1956) 1303.

10. A. B. Devale, D. K. Kulkarni, J. Pure and Appl. Phys. 16:697:1978.

11. R. H. J. Waldron, Appl. Phys. (USA), 43 (1972) 1186.

12. Yu. P. Irkin, E.A. Turov, Soviet Phys. JEPT, 33:673:1957.

13. K. R. Krishanamurthy, Thesis I.I.T., Madras (1975). 